\title{
EL CELTIBÉRICO, DIALECTO ARCAICO CELTA ${ }^{1}$
}

The present paper, which is divided into four parts, analyses the most characteristic features of the Celtiberian language in the framework of Celtic dialectology. In the first two parts, we outline the general criteria for the evaluation of the linguistic data of a language fragmentarily recorded, as well as the contribution which can be made to the dialectology of the Celtic languages from Celtiberian and continental Celtic. In the third part, we analyse the features which Celtiberian shares with the other Celtic languages and the innovations which it presents with respect to other Indoeuropean languages. Besides the traditional phonological and morphological arguments, aspects of the lexicon are also discussed, especially the designations for the name of 'son'. Finally, in the last part, the special arcaisms of Celtiberian relative to other Celtic languages are evaluated, together with the historical consequences which derive from the early separation of hispanic Celtic from the general Celtic community.

Para un lingüista son lenguas célticas aquellas que, todavía vivas o bien ya desaparecidas, comparten mutuamente en los diferentes ámbitos de sus gramáticas - fonología, morfología y sintaxis - unas características tales, que por un lado las hacen partícipes de una familia más extensa de lenguas, las llamadas lenguas indoeuropeas, y por otro lado las delimitan claramente como un subgrupo de la misma familia, oponiéndolas a otros grupos semejantes: germánico, itálico, eslavo, indo-iranio, griego, etc. No cabe duda de que una clasificación de este tipo está basada en unos criterios que, aunque sean ampliamente aceptados, son en el fondo arbitrarios. Se necesita un buen puñado de rasgos semejantes en todos los ámbitos de la gramática, desde la fonología hasta el léxico, para poder decidir con cierta seguridad acerca de la subclasificación ge-

1 Este trabajo ha sido realizado en el marco del Proyecto de Investigación PB 90-0623 de la DGCYT del Ministerio de Educación y Ciencia y constituye la versión corregida de una conferencia leída en la Universidad Internacional Menéndez y Pelayo en Valencia en 1993. 
nética de una lengua. Pero en el fondo el principio clasificatorio es sencillo: todos los rasgos que unas determinadas lenguas comparten en exclusividad son proyectables a la lengua madre de la que derivan, que recibe el nombre de protolengua o lengua común del grupo correspondiente. A veces se piensa que el trabajo de la reconstrucción de esta protolengua es sólo necesario en el caso en que no se halle documentada por escrito, p. ej. el protogermánico o el protoeslavo, siendo superflua la reconstrucción de un protorrománico porque en este caso contamos con el latin. Sin embargo, el trabajo de muchos romanistas y algunos latinistas consiste precisamente en la reconstrucción de esa lengua común a todos los romances, haciendo abstracción de la existencia del latín. Gracias a este trabajo paciente y puntilloso un romanista sabe que el español oigo no procede regularmente de lat. audio, sino que ha sustituido a otra forma oyo, que es la esperada en este caso. Se supone que todos esos rasgos comunes, y a la vez exclusivos de las lenguas que forman el subgrupo, han sido heredados de su lengua madre, la cual evolucionó en ese sentido - los biólogos dirían «mutó»-, a partir de un estado de lengua anterior, su lengua madre, en nuestro caso el indoeuropeo. De modo que a la hora de la subclasificación, son de gran valor las mutaciones comunes, las sinapomorfias que dirían los biólogos sistemáticos, sin que los rasgos compartidos con otras lenguas de otros grupos signifiquen más que el hecho de que pertenecen a un tronco común, a una familia más extensa, algunas o muchas de cuyas características siguen conservando. En lingüistica este principio fue formulado explícitamente por Leskien ${ }^{2}$ en 1876 («los criterios para una comunidad más estrecha sólo pueden hallarse en coincidencias positivas entre las lenguas correspondientes, que al mismo tiempo son separaciones de las restantes") $)^{3}$. Pero, aunque el principio sea sencillo y cuente con un con-

2 A. Leskien, Die Declination im Slavisch-Litauischen und Germanischen, Leipzig 1876: «Die Kriterien einer engeren Gemeinschaft können nur in positiven Uebereinstimmungen der betroffenden Sprachen, die zugleich Abweichungen von den übrigen sind, gefunden werden").

${ }^{3}$ Sobre la identidad de los principios clasificatorios en lingüística histórico-comparada y en biología, véase, p. ej., Maryellen Ruvolo, «Reconstructing genetic and linguistic Trees: phenetic and cladistic approaches", en Biological Metaphor and Cladistic Classification (edd. H. H. Hoenigswald \& L. F. Wiener), 1987, esp. p. 194: «Phenetic and cladistic analyses differ in their classifying and handling of similarities between taxa. Prior to Hennig (1966), biologists thought of similarities in a dyadic way. A similarity between two taxa was either 'real' because it reflected shared inheritance, or was not real because it represented the same, convergent solutions to some evolutionary challenge. Hennig broke up this dyadic scheme into a triadic one by splitting the category of 'real' or inherited similarities. He distinguished between taxa resembling each other (1) because they inherit a trait from a remote common 
senso generalizado, los problemas empiezan cuando se desciende al terreno concreto de la valoración de cada rasgo o taxon: hay que decidir en cada caso si se trata de un arcaísmo, es decir del mantenimiento de un rasgo antiguo o simplesiomorfia, o bien de una innovación o sinapomorfia. También existen casos de innovaciones paralelas, que favorecen grandemente la similitud final y que sólo son detectables como tales innovaciones paralelas si se cuenta con una historia y una cronología relativa de los fenómenos bien establecida. P. ej. tanto el griego como el indio sufrieron una deaspiración de la primera consonante aspirada en toda palabra que contara con otra aspirada subsiguiente, circunstancia que recibe el nombre de ley de Grassmann. A pesar de que se trate de las únicas lenguas de la familia en sufrir este curioso fenómeno, la fecha en que tal proceso ocurrió en la historia de cada una de ellas debió ser totalmente diferente, puesto que sabemos que antes de tal circunstancia ambas lenguas había evolucionado independientemente en muchos aspectos.

Pero en lenguas no muy alejadas o en dialectos es muy dificil decidir acerca del carácter independiente o común de algunas evoluciones idénticas. Suele ocurrir también muchas veces que en una familia o grupo dialectal haya una tendencia general hacia determinados cambios, que ocurren en cada lengua de manera independiente y en fechas diferentes: un ejemplo típico puede ser el umlaut de las lenguas germánicas occidentales. (Drift de Sapir.)

El lingüista debe valorar, pues, caso por caso cada uno de los rasgos y decidir si se trata de una innovación o bien de un rasgo banal para la clasificación, y en este proceso de valoración surgen las diferencias entre los especialistas; la historia de la disciplina está plagada de discrepancias, entre las cuales la posición designada al hitita en el conjunto de la familia ha resultado ser, sin duda, la más notoria de todas ellas. Es cierto que la lingüística histórica está basada en el axioma de que los cambios fonéticos experimentados por una lengua son regulares, procesos a los que los neogramáticos tildaban de «leyes», y en el principio de la imposibilidad de la escisión arbitraria o incondicionada de un fonema - pero sí de la posibilidad de una fusión incondicionada - razón por la que dos sistemas fonológicos sucesivos en una misma línea de transmisión presenten una relación mutua idéntica a la que presentan entre sí dos conjuntos homomorfos en la teoría de conjuntos. Pero junto a esto, que es importantísimo y constituye el esqueleto sobre el que

ancestor and (2) because they share a newly evolved trait unique to them and their immediate common ancestor". 
se alza toda la construcción posterior, existe gran cantidad de opiniones cuya máxima virtualidad es la de su verosimilitud ${ }^{4}$.

Las lenguas célticas tardaron en ser estudiadas científicamente en el seno de la familia indoeuropea, ya que hubo que esperar a la obra de J. C. Zeuss en 1853 para establecer su clasificación y relaciones con el resto de las lenguas indoeuropeas ${ }^{5}$. La rama céltica está constituida en la actualidad por dos grupos de lenguas: por un lado el irlandés hablado en Irlanda, el escocés llevado desde Irlanda a Escocia en el s. v d. C. y la lengua de la isla de Man forman el grupo goidélico o gaélico, mientras que, por otro, el galés del País de Gales, el córnico, lengua de Cornualles extinta desde finales del xviII, y el bretón, hablado en la Bretaña francesa, forman el grupo britónico o británico de la rama. Es evidente que este último nombre procede del de Britannia, nombre que los romanos tomaron de los geógrafos griegos; Piteas de Marsella hacia el 325 a. C. es el primero en hablar de Преттavia, cuya $p$ inicial está justificada etimológicamente por el gal. Prydein $<{ }^{*} k^{\sharp} r i t a n \bar{l}$ 'los pintados' (cf. Picti de las tierras altas de Escocia). Tradicionalmente se sostiene que el bretón es el derivado de un dialecto britónico del suroeste de Gran Bretaña, por tanto más cercano al córnico que al galés, que fue llevado al continente entre los siglos v y vi d. C. como consecuencia de la presión ejercida por las invasiones sajonas sobre la isla. Es también posible la idea lanzada por Falc'hun ${ }^{6}$ de que los britones se superpusieran a una población hablante aún de galo, que como luego veremos debía presentar ciertas similitudes con las hablas de la isla. El grupo goidélico recibe su nombre del término irl. ant. goidelg 'lengua irlandesa', que es a su vez un préstamo del galés gwyddeleg, basado sobre el galés gwydd 'salvaje, incultivado'. Aparte de tratarse de un claro ejemplo de adopción de nombre étnico de origen extraño, nos informa de dos aspectos interesantes: uno, que los britanos, aculturados en la civilización romana y las letras consideraban a los irlandeses, que nunca fueron ro-

${ }^{4}$ L. Michelena, Lenguas y Protolenguas, San Sebastián $1990_{3}$ (= Languages and Protolanguages, Bilbao UPV [en prensa]).

5 J. Gaspar Zeuss, Grammatica celtica, Berlín 1853. La segunda edición, a cargo de H. Ebel, apareció en Berlín en 1871.

"F. Falc'hun, "Celtique continental et celtique insulaire en breton", Annales de Bretagne 70, 1963, pp. 425-54; L. Fleuriot, «Brittonique et gaulois durant les premiers siècles de notre ère", Etrennes de septantaine. Travaux de linguistique et de grammaire offerts à M. Lejeune, París 1978, pp. 75-83. 
manizados, poco cultivados, y por otro lado, que los irlandeses no debían entender el sentido peyorativo del término britónico cuando lo tomaron en préstamo como designación de su propia identidad etnolingüística.

Estas dos ramas del grupo céltico fueron caracterizadas por los respectivos resultados que en cada una de ellas recibe el tratamiento de la labiovelar sorda indoeuropea ${ }^{*} k^{\mu}$ : a) mantenimiento primero y pérdida del redondeamiento labial en goidélico, b) paso a labial $p$ en britónico. El propio nombre de Britania ofrece un ejemplo del tratamiento, ya que frente al galés Prydein tenemos el irl. ant. Cruithen-túath 'pueblo picto' ${ }^{*} k^{u}$ riteno-toutā con consonante velar. Otros ejemplos clásicos son el numeral cuatro: gal. pedwar, irl. a. ceth(a)ir $<{ }^{*} k^{4} e t u \bar{o} r e s$ o el pron. interrogativo: gal. pwy: irl. a. cía. $<{ }^{*} k^{*} e i$. Se habla, por tanto, de celta P- o britónico y celta Q- o goidélico. Este tratamiento le sirvió de argumento básico a $\mathrm{A}$. Walde ${ }^{7}$ para establecer una estrecha vinculación de cada una de estas ramas con cada una de las dos ramas itálicas: a saber, del goidélico con el latín-falisco en cuanto conservadores de la labiovelar y del britónico con el osco-umbro como innovadores en su paso a labial: p. ej. frente al interrogativo latino quid el osco tiene pid. Aunque algunos estudiosos, como Pisani, no mantuvieran la misma idea que Walde, seguían basándose en esta diferencia para sustentar una especial relación histórica entre las respectivas ramas. Pero ya Marstrander ${ }^{8}$ se encargó de echar por tierra el argumento, mostrando que las evoluciones son paralelas, pero totalmente independientes en cada subgrupo; en concreto el tratamiento de la labiovelar sorda en celta ocurre después de la desaparición de * $p$ (oclusiva labial sorda) en todo el grupo, rasgo que considera común a todas las lenguas célticas, y que no afecta en absoluto al itálico: así, p. ej., al lat. pater corresponde irl. a. aithir.

Los lingüistas han ido estudiando los cambios producidos en cada una de las ramas y han configurado las características principales que comparten, así como los rasgos propios e individuales de cada una de ella. Hay que decir, en este lugar, que la idea que se tiene sobre las lenguas célticas procedía exclusivamente de estas lenguas vivas, cuyos estadios documentados más antiguos nunca superan los primeros siglos de la Edad Media. Los documentos más antiguos lo constituyen las llamadas inscripciones ogámicas, que están redactadas en una fase especial-

7 A. Walde, Uber älteste sprachliche Beziéhungen zwischen Kelten und Italikern, Rektoratsschrift, Innsbruck 1917.

${ }^{8}$ C. J. S. Marstrander, "De l'unité italo-celtique», NTS 3, 1929, pp. 341-359. 
mente arcaica de la lengua irlandesa; los textos más antiguos remontan al s. v d. C., siendo los más numerosos del vi y vil d. C.; el llamado irlandés antiguo clásico se atestigua mayoritariamente en los monasterios centroeuropeos fundados y regentados por monjes irlandeses durante los ss. VIII y Ix. En el lado britónico somos aún menos afortunados, ya que los textos galeses son en su mayoría del s. XI y XII en adelante, aunque un número significativo de glosas e inscripciones a partir del $s$. vi d. C. conforman el corpus del galés antiguo; con anterioridad hay solamente unas pocas inscripciones y material onomástico vario, alguno más antiguo que el propio goidélico ya que remonta a la época de la ocupación romana de la isla ${ }^{9}$. Siempre ha habido conocimiento del galo, aunque sólo fuera por las explícitas afirmaciones de César en sus Comentarios y por los numerosos nombres de persona transmitidos en su obra o en epígrafes de época imperial, pero su peso y consideración en la idea acerca del celta, y me estoy refiriendo al celta como lengua, no al celta como cultura lateniana, era realmente insignificante. Con esto quiero llamar la atención sobre la paradoja en que se ha vivido durante muchos años, en virtud de la cual la cultura gala lateniana con su civilización opidana, su noble aristocracia, sus suntuarios enterramientos, sus carros, sus templos o nemeta, era la expresión material más genuina de lo celta, mientras que la tradición religiosa, literaria y espiritual de los celtas era encarnada más fielmente por los textos más antiguos de Irlanda, territorio que destaca por la nula o escasísima presencia de los elementos culturales que configuran la celticidad gala ${ }^{10}$.

Estos datos galos, que en muy corta medida ofrecían alguna información gramatical aparte de consideraciones onomásticas, fueron integrados dentro de la perspectiva celta, en concreto en estrecha relación con la rama britónica, como elementos que venían a confirmar las conjeturas reconstructoras obtenidas a partir de la comparación de las lenguas neocélticas. Es el estado que presentan los manuales clásicos como el de Pedersen sobre la gramática comparada del celta ${ }^{11} \mathrm{o}$ el de Thurneysen sobre el irlandés ${ }^{12}$. Solamente con la importante ampliación de documentación epigráfica que ha tenido lugar a lo largo de este siglo y

${ }^{9}$ Para una historia concisa de la lengua galesa, véase ahora en versión alemana el libro de H. Lewis, Die Kymrische Sprache. Grundzüge ihrer geschichtlichen Entwicklung, Innsbruck 1989.

${ }_{10}$ Sobre esta cuestión, cf. Mac Eoin, "The celticity of Celtic Ireland», en Geschichte und Kultur der Kelten (ed. K. H. Schmidt con ayuda de R. Ködderitzsch), Heidelberg 1986, pp. 161-174.

$"$ H. Pedersen, Vergleichende Grammatik der keltischen Sprachen, dos vols., Gotinga 1909, 1913.

${ }_{12}$ R. Thurneysen, A Grammar of Old Irish, Dublin 1964. 
gracias a la atención que le dedicaron estudiosos como L. Weisgerber ${ }^{13}$, a quien se debe la acuñación del término Festlandkeltisch o celta continental, o J. Whatmough, autor de una erudita obra de recopilación de material ${ }^{14}$, fue tomando el galo un papel cada vez más importante en el seno de los dialectos celtas. Con la reciente aparición de textos de longitud respetable, como las inscripciones de Chamalières o Larzac en el dominio galo, la identificación del lepóntico, gracias a Lejeune, como dialecto independiente del celta continental, cuyos documentos más antiguos han sido elevados últimamente hasta el s. vi a. C., y la importancia cada vez mayor que muestran los textos celtibéricos, ya nadie puede relegar la información que ofrecen estos dialectos continentales, que aunque escasa en número y a veces de muy dificil interpretación, aventaja en muchos siglos a los más viejos textos insulares.

En los trabajos pioneros y fundacionales de Tovar (Estudios) sobre la lengua celtibérica se pone de relieve uno de los rasgos fonológicos más importantes de estas lenguas: la pérdida de la oclusiva bilabial sorda del indoeuropeo $\left({ }^{*} p\right)$ en posición inicial e intervocálica, al interpretar la secuencia VIROS VERAMOS, en el santuario rupestre de Peñalba de Villastar, como uir supremus a partir de una forma indoeuropea anterior *uper-m̧mo- superlativo del adverbio *uper-, cf. gr. únદ $\rho$, lat. $(s) u$ per, scr. upari. Todos los demás dialectos celtas participan de esta innovación: irl. for-, gal. gwor-, galo Ver-, lep. Uvamo- sobre el adv. *upo. Este rasgo ha sido confirmado sin ninguna duda en el bronce de Botorrita, donde la forma verbal roBiśeTi presenta el preverbio ro-, procedente del IE * pro-, muy conocido por cualquier estudiante de griego o de latín, y representado en irl. por el prefijo y preverbio ro- de valor perfectivo y en galés por el prefijo intensivo rhy. Igualmente el nombre de la ciudad de areCoraTa está formado mediante el prefijo are-, procedente de ari- aún apreciable posiblemente en la grafia areiCoraTiCoś del étnico, que remonta al IE * $p^{o} r i$ - (cf. gr. mapá), representado en irl. por el pref. air-, en galés por ar-, er-y en galo por Are-, como en el nombre del famoso pueblo de los Aremorici, antecesor del actual nombre de la región de Armórica, literalmente «los situados cerca del mar».

${ }^{13}$ L. Weisgerber, «Die Sprache der Festlandkelten», Römisch-Germanische Kommission 20, 1931, pp. 147-226 (= Rhenania Germano-Celtica, Bonn 1969, pp. 11-85).

14 J. Whatmough, The Dialects of Ancient Gaul, Cambridge 1970, Harvard U. P. 
Sin abandonar el tratamiento de la ${ }^{*} p$ indoeuropea, el celtibérico participa también de un cambio general del celta: *-ps- $>-k s-$, como se aprecia en el famoso nombre de ciudad Uxama y en el de su étnico en escritura epicórica uśamus, que se analizan como formas de superlativo sobre la base adverbial *ups- 'encima, sobre', cf. gr. ü $\psi$.

Otra innovación fonológica exclusiva del celta consiste en el tratamiento con timbre $i$ de las sonantes vocálicas líquidas ante oclusiva: ${ }^{*} r>r i,{ }^{*} l>l i$, p. ej. brig- como segundo elemento de topónimos como nerToBiś en grafia defectiva por [nerto-briks] o [-brixs], a partir de *-bhrgh-. En Galia hay numerosos topónimos en -briga y el término está atestiguado en irl. a. como bri 'colina' y en galés como bre. La palabra muestra además el resultado sonoro de las antiguas aspiradas indoeuropeas que, aunque fenómeno atestiguado en otros dominios dialectales indoeuropeos (cf. eslavo, iranio, etc.), es rasgo privativo del celta entre las lenguas occidentales. El tratamiento de la líquida puede ejemplificarse probablemente en Con-śCiliTom (A3), adjetivo verbal *kon-skl-tó- de la raíz verbal *skel- 'cortar'.

Como último ejemplo del ámbito de la fonología, es significativo el tratamiento de la labiovelar sonora ${ }^{*} g^{\mu}$ ya que en todos los dialectos celtas dio como resultado una labial sonora [b]: CI. BouśTom algo así como 'cuadra de vacas' a partir del término para 'vaca' ${ }^{*} g^{\mu} \bar{o} u-$, cf. irl. a. bó, gal. med. bu. Aunque la labialización de labiovelares es un fenómeno fonético fácilmente explicable, que tiene lugar en otras lenguas indoeuropeas, como en griego o en osco-umbro, las condiciones y resultados de estos procesos son diferentes; así p. ej. en osco-umbro la labialización es incondicionada y afecta por igual a toda la serie, tanto a la oclusiva sonora como a la sorda y a la aspirada: ${ }^{*} k^{*}>p,{ }^{*} g^{\mu}>b$, ${ }^{*} g^{\prime \prime} h>f$, mientras que en griego depende del contexto fonético circundante. En cambio en celta la sonora evoluciona siempre, excepto ante yod, a labial, mientras que la sorda se mantiene en principio como labiovelar, cambiando más tarde a $/ p /$ sólo en determinados dialectos (lepóntico, galo y britónico), como ya hemos dicho más arriba. En cuanto al tratamiento de la labiovelar aspirada hay opiniones diferentes, destacando la tradicional de Osthoff o Thurneysen, según la cual ${ }^{*} g^{4} h>g$, la de Lewis-Pedersen y otros que admiten un tratamiento diferenciado para el goidélico $\left({ }^{*} g^{*} h>g\right)$ y para el britónico $\left({ }^{*} g^{u} h>b\right.$, al menos en posición intervocálica, cf. § 39) y la de Cowgill que propone ${ }^{*} g^{\sharp} h>g w$ con generalidad para todo el celta ${ }^{15}$.

15 No se ha hallado aún en los textos celtibéricos ninguna palabra cuya etimología remonte a una forma indoeuropea con labiovelar sonora aspirada. La sugerencia 
También en el terreno de la morfología nominal y verbal pueden hallarse rasgos comunes a todas las lenguas célticas, aunque en este ámbito sea más dificil reunir un puñado de innovaciones con respecto a otras lenguas indoeuropeas. Un ejemplo claro lo ofrecen los pronombres relativo y demostrativo, que aparecen en una secuencia correlativa en el Bronce de Botorrita: iomui...śsmui 'a quien..., a ese..... Apreciamos que el pronombre relativo celtibérico es ioś, en lo que coincide con el resto de las lenguas célticas, tal como observamos en galo -io pospuesto al verbo dugiontiio 'que veneran' en la inscripción de Alesia y se deduce por ciertas formas verbales relativas del irl. ant., p. ej., téite 'que va' $<{ }^{*}$ steig-e-t-io y del galés, p. ej., $y$ sydd, forma relativa de la cópula $\left(<{ }^{*}\right.$ est-io). En el empleo de ${ }^{*}$ io- como relativo coincide con otras lenguas indoeuropeas, como el griego y el indio antiguo, pero se separa significativamente del resto de las lenguas indoeuropeas occidentales vecinas, tanto del itálico como del germánico, que utilizan otras raíces para esta función, en concreto la del interrogativo-indefinido ${ }^{*} k^{\psi} O$ - en itálico. Se trata, por tanto, de un rasgo no exclusivo del celta, que remonta a una antigüedad mayor y cuya explicación está sujeta a interpretación en el marco de la dialectología indoeuropea: o bien la lengua originaria tenía ambas posibilidades, dándose una elección por cada una de las variantes en los dialectos herederos, o bien, teniendo en cuenta que el hitita también emplea la raíz ${ }^{*} k^{u} o$ - para el relativo, se trata de una innovación de un determinado conjunto de dialectos, entre los que se hallaba el celta común, antecesor de todas las lenguas célticas históricamente atestiguadas ${ }^{16}$.

de J. Untermann («Los teónimos de la región lusitano-gallega», Actas del III Coloquio sobre Lenguas y Culturas paleohispánicas, Salamanca 1985, p. 356, repetida más recientemente en "Anotaciones al estudio de las lenguas prerromanas del Noroeste de la Península Ibérica", Galicia: da romanidade a xermanización. Problemas históricos e culturais, Santiago de Compostela 1992, p. 374) de que el epiteto de la divinidad lusitana de Caldas de Vizela Bormanicus pueda reposar sobre el adjetivo indoeuropeo * $g^{*}$ hormo- 'caliente' no está libre de discusión, ya que puede asimismo basarse sobre *bhor-mo/-uo- 'bullir'. En cambio el término portugués gorar 'no hacer polluelo' y el cast. ant. gorar 'incubar', de donde port. goro y cast. huero (cast. ant. güero), etcétera, se relacionan con el galés gori 'incubar' de * $g^{\star}$ hor- y mostrarian en la península un resultado $\mathrm{g}$ (cf. Corominas, Diccionario crítico etimológico de la lengua castellana, s.u. huero). Con este étimo se ha relacionado también el vasco gori 'ardiente, rusiente'. El problema del tratamiento de la labiovelar aspirada en céltico ha sido estudiado recientemente por Kim McCone («The PIE Stops and Syllabic Nasals in Celtic», Studia Celtica Japanica 4, 1991, pp. 37-69), que se inclina por un proceso IE ${ }^{*} g^{*} h>$ celta común ${ }^{*} g^{\star}$, que luego se diferencia en goidélico $g$, galo $w$ y britónico $g w-0-b->-v-$.

${ }_{16}$ Para un posicionamiento dialectal del celta en un ámbito cercano al del indoiranio y griego, véase $\mathrm{K}$. H. Schmidt, «Latín y celta: parentesco lingüístico y relaciones areales», Veleia 8-9, 1991-92, p. 269. ss. 
En cambio, el demostrativo muestra una innovación específica del grupo; por otras lenguas, en concreto por el griego, sabemos que este pronombre mostraba una alternancia entre el nom. sg. de los animados, es decir del masc. ${ }^{*} s o$ y del fem. ${ }^{*} s \bar{a}$, y el resto de las formas, que se declinaban sobre el tema ${ }^{*} t o-$, como lo demuestra el artículo griego $\delta$, $\eta$, Tó $\left(<{ }^{*}\right.$ so, sā, tod). En celta hubo una innovación, según la cual el tema del nominativo animado se impuso a todas las formas flexivas, mediante un proceso de extensión analógica, de modo que como dat. sg. masc. en CI tenemos śomui en vez de *to-(s)mui, cf. ind. a. tásmai, gót. thamma, todavía en ingl. them. Compárese con el demostrativo galo $\operatorname{sosin}$ (ac. sg.) o el artículo neutro del irlandés ant. $a^{n}\left(<{ }^{*} s o-m\right){ }^{17}$, en los que el tema so- es también nuevo.

Algunos numerales, en concreto ciertos ordinales, muestran una innovación típica, consistente en la utilización del sufijo -eto- en lugar de otros indoeuropeos como -o- o bien -to-. El latín nos muestra, por ejemplo, que frente al cardinal septem tenemos el ordinal septim-us, junto a decem, decim-us y junto a quinque, quinc-tus. En cambio el galo, que presenta toda la serie de ordinales, tiene decam-etos para 'décimo', sextam-etos para 'séptimo' y pimp-etos para 'quinto'. Construcciones idénticas se hallan en irlandés y galés, para cuya ejemplificación valdrá aducir la respectiva forma para décimo: irl. dechmad y gal. degfed. La explicación para este fenómeno consiste en que hubo una remodelación del ordinal 'quinto' a partir del cardinal 'cinco' de modo que una forma anterior ${ }^{*} k^{\psi} e n k^{\mu}$-to, conservada en lat. quīnc-tus o en griego $\pi \dot{\varepsilon} \mu \pi-\tau o \zeta$, se remodeló en ${ }^{*} k^{u} e n k^{\mu} e$-to, de donde irl. a. cóiced y galo pimpetos. Después no hay más que suponer que de esta relación se obtuvo un sufijo secundario muy claro -eto-, que fue utilizado para la formación de los cardinales entre séptimo y décimo. El celtibérico en su bronce de Botorrita atestigua una palabra TeCameTinaś que con el sentido de 'diezmo' se entiende como formación derivada mediante el suf. -ino- a partir del ordinal decametos 'décimo'. Si la explicación ofrecida arriba sobre la innovación de los ordinales célticos en -etos es correcta, hay que suponer que el celtibérico también contó con un ordinal *quinquetos para 'quinto', origen de la extensión analógica, aunque no esté por ahora atestiguado. Si tenemos alguna fe en este tipo de argumentación, deberemos concluir necesariamente que otras formaciones diferentes atestiguadas en otros lugares de Hispania, en concreto en su zona más Occidental, como la serie de antropónimos Pentius, Pintius y derivados, que se han

${ }^{17}$ Patrizia de Bernardo, «Indogermanische Demostrativa und der altirische Artikel», ZCP 41, 1986, pp. 259-271. 
puesto en relación con el ordinal 'quinto' ${ }^{18}$, no pueden considerarse celtas, porque no participan de, al menos, dos innovaciones que consideramos generales en el grupo: la pérdida de ${ }^{*} p$ inicial antevocálica y la formación en -eto-, sin contar con la típica asimilación de la secuencia ${ }^{*} p \ldots k^{\mu}>{ }^{*} k^{u} \ldots k^{\mu}$, sobre cuya aplicación generalizada pueden concebirse más dudas ${ }^{19}$.

Los ejemplos de innovación común aducibles en el campo de la morfología verbal son más dificiles de definir; en primer lugar, la misma naturaleza de los textos continentales, con una relativamente escasa representación de formas verbales y en todo caso reducidas, por lo general, a unas limitadas formas estereotipadas de dedicación o realización, no favorecen la labor comparativa; por otro lado, los rasgos eminentemente comunes remontan a un estadio indoeuropeo, o al menos dialectal dentro del indoeuropeo, por lo que no son de tanta utilidad a la hora de configurar las innovaciones propias del celta común en este terreno. Ocurre también que ciertos rasgos sólo pueden proyectarse al celta común por el hecho de que sobreviven en alguno de los dialectos celtas históricos, pero no en todos, tras ser eliminada la posibilidad de que se trate de una innovación parcial dentro del grupo celta, limitada precisamente a esos dialectos que la muestran. Por ejemplo, aunque aún no se hayan detectado en celtibérico formas de pasado procedentes del aoristo sigmático indoeuropeo, hay que suponer que el celta común las conocía, en virtud de las formas de pretérito en - $t$ del irlandés (-bert $<{ }^{*}$ ber-s- $t$ ) o de las formas galas de pretérito como prinas 'ha comprado' ( $\left.{ }^{*} k^{u} r i-n a-s-t\right)$; en cambio el celtibérico atestigua formas temáticas de subjuntivo o futuro en *-se-/so- (p. ej. amBiTiśeTi (A5) 'construya alrededor'), con paralelos en otras lenguas indoeuropeas como el griego, que pueden relacionarse ahora con las formas irlandesas de subjuntivo en $-s\left(3 .{ }^{a} s g\right.$. pres. subj. conjunto -ain 'proteja' < *aneg-s- $t$, cf. pres. ind. aingid). La diferencia entre la flexión temática del celtibérico y la fle-

18 Véase U. Schmoll, Die Sprachen der vorkeltischen Indogermanen Hispaniens und das Keltiberische, Wiesbaden 1959, p. 47 s.

19 El conocido término del galo meridional $\delta \varepsilon \kappa a v t \varepsilon \mu$ ha suscitado muchos comentarios, tanto por su desinencia como por su formación. Parece que se trata de uná antigua forma de ordinal, anterior por tanto a la innovación céltica y gala en -eto-, que con el valor técnico secundario de 'diezmo' pervivió en galo como arcaísmo. Recuérdese la cuarta ley de Kurylowicz. Sobre la no aplicación generalizada del cambio ${ }^{*} p \ldots k^{*}>{ }^{*} k^{*} \ldots k^{*}$ puede citarse el gen. dëac, déec del cardinal deich 'diez' que GOI, § 392 hace proceder de *duei-penk" ${ }^{*}$. Por otro lado, dependiendo de la cronología relativa de la aplicación de ciertos procesos, p. ej., que la pérdida de labialidad de la labiovelar ante oclusiva * penk $k^{*}$-to- $>{ }^{*}$ penk-to-, como ocurre en la mayoría de las lenguas indoeuropeas, sea temprana, resultaría que ambas reglas se hallarian en un orden bleeding. 
xión atemática del irlandés, que formalmente no se diferencia en nada de los pasados en $-s$, la explica Schmidt ${ }^{20}$ como una reordenación irlandesa de las dos flexiones originarias, representadas en celtibérico y en galo respectivamente.

En sintaxis es también dificil hallar rasgos comunes que sean a la vez verdaderamente innovadores, dada la diversidad sintáctica en el orden de constituyentes que ofrecen las lenguas célticas históricas: así el CI muestra un orden básico SOV, como puede apreciarse en esta secuencia correlativa formada por una oración relativa más la principal:

A 8: iaś osiaś uerTaTośue Temeiue roBiśeTi, śaum TeCameTinaś TaTus.

Aunque el sentido de estas frases no sea todavía claro, está fuera de toda duda que la primera oración comienza con un pron. relativo femenino en acusativo de plural (iaś), con el que concierta otro pronombre (osiaś); le siguen dos adverbios unidos por la conjunción disyuntiva enclítica -ue y acaba la oración con una forma de $3 .^{\mathrm{a}}$ pers. sg. de un futuro-subjuntivo en *-se- de un verbo compuesto del preverbio ro-, de valor perfectivo o intensificativo, más una raíz no identificable con exactitud. La segunda oración comienza con el pronombre demostrativo śaum, del que hemos hablado antes, en gen. pl. femenino que hace referencia a los objetos o seres femeninos plurales introducidos por el pronombre relativo de la oración anterior, al que le sigue TeCameTinaś, ac. pl. del nombre del 'diezmo' más el verbo en una forma realmente poco esperada, pero cuyo valor imperativo está prácticamente asegurado; es decir 'de éstas (cosas) dé diezmos'. El lepóntico también coincide con el celtibérico en un orden SOV, como puede apreciarse por la inscripción de Prestino, citada más adelante.

El galo, por su parte, presenta ejemplos de un orden más variado, siendo más numerosas las oraciones con un orden SVO, aunque no falten ejemplos de oraciones con verbo al final ni con verbo inicial, sobre todo las de relativo; en cambio el celta insular, sobre todo el irlandés, muestra un orden VSO muy estricto, que desde siempre ha llamado la atención de los lingüistas por su rareza en el seno de la familia indoeuropea. Hay un consenso generalizado en que el orden celtibérico es el más arcaico de los tres, porque coincide con el orden atestiguado en los más antiguos testimonios del latín, del védico y del hitita. Esta presunción puede ser apoyada también por el irlandés, que muestra en su lite-

${ }^{20}$ K. H. Schmidt, «Zur Rekonstruktion des Keltischen. Festlandkeltisches und inselkeltisches Verb", ZCP 41, 1986, pp. 159-179. 
ratura legal más arcaica ejemplos de verbo en posición final y de tmesis estudiados por $\mathrm{O}$. Bergin. Ha habido varios intentos de explicar los procesos históricos que han llevado de un orden prehistórico SOV a un orden histórico VSO, entre los cuales el trabajo de Watkins de 1963 es central ${ }^{21}$. Algunos lingüistas han achacado este cambio tan radical a una influencia de sustrato, causada por lenguas no indoeuropeas de una vieja capa afro-europea occidental y atlántica, de la que las lenguas camíticas serían sus más eximios representantes actuales ${ }^{22}$. El orden de palabras de las lenguas britónicas ha suscitado mucho interés recientemente, ya que frente a la idea tradicional, defendida por muchos, de un orden básico VSO idéntico al del irlandés, se ha defendido, principalmente por Koch, que el orden normal del britónico era con verbo en segunda posición ${ }^{23}$.

Hay rasgos significativos como el gran papel de los sustantivos verbales en sintaxis, bien atestiguados también en celtibérico, que muestran el carácter arcaico del celta a este respecto, que no ha creado una categoría como la del infinitivo. Las lenguas célticas insulares carecen también de un verbo específico para expresar la noción de 'tener', para lo que recurren al giro antiguo de verbo sustantivo más dativo, semejante al latino est mihi. Como hay buenas razones para pensar que este rasgo es una característica del indoeuropeo común, sobre todo si se piensa que el proto-indoeuropeo era una lengua de tipo activo y no de tipo acusativo como lo sería más tarde ${ }^{24}$, es de suponer que en Celtibérico no hallemos un verbo con el sentido del latino habere ${ }^{25}$ o gót. haban, ni gr. $\varepsilon_{\chi} \varepsilon v v$, etc. De todos modos, si ocurriera esto, estaríamos en la obligación de entenderlo como una innovación particular del celtibérico, tenida lugar después de la separación de esta lengua del tronco común familiar.

${ }^{21} \mathrm{C}$. Watkins, «Preliminaries to a historical and comparative analysis of the syntax of the Old Irish Verb", Celtica 6, 1963, pp. 1-49.

${ }^{22}$ Véase el trabajo de $\mathrm{H}$. Wagner, "The Origin of the Celts in the light of linguistic Geography", TPhS, 1969, pp. 203-250 (= Studies in the Origins of the Celts and of early Celtic Civilisation, Belfast-Tubinga 1971).

${ }^{23}$ Sobre este problema puede verse el libro Studies in Brythonic Word Order (J. Fife y E. Pope, edd.), Amsterdam 1991, en el que John T. Koch defiende el orden con verbo en segunda posición en su trabajo "On the Prehistory of Brittonic Syntax", pp. 1-43, mientras que Proinsias Mac Cana justifica a partir de la literatura galesa medieval el orden VSO en "Further Notes on constituent order in Welsh", pp. 45-80.

${ }^{24}$ Winfred P. Lehmann, The theoretical bases of Indo-European linguistics, Londres-Nueva York 1993, pp. 221-2.

${ }_{25}$ En el BB se documenta, sin embargo, CaBiseTI que remonta a ${ }^{*}$ ghabh-, la misma raiz que la de lat. habere, aunque el sentido originario no era el de 'tener', sino el de 'tomar', conservado en celta. 
Y por último, el léxico constituye otro dominio en el que se puede basar y comprobar la celticidad de las lenguas del grupo. Hay que decir que el léxico por sí solo no tiene una excesiva capacidad probativa, pero en unión con los otros criterios que acabamos de mencionar resulta altamente significativo. Este poder probativo aumenta si el léxico presenta, como en el resto de los niveles gramaticales aducidos, alguna especie de innovación en su formación o en su sentido. El celtibérico muestra algunos vocablos muy significativos en su celticidad: entre ellos, sin duda, el más relevante lo constituye el término -brig(a) empleado en la formación de nombres de ciudad. Coincide en ello con el galo-britónico y con el goidélico, que atestiguan también nombres de ciudad en -briga. El término, con este sentido de oppidum es una especialización de la raiz ${ }^{*} b h r g h-$, que significa 'altura, elevación', atestiguada en el propio celta (irl. a. bri 'colina') y en otros grupos indoeuropeos como el germánico (p. ej. al. Berg 'montaña'). En celta, la raíz fue muy productiva en la formación de étnicos, p. ej. Brigantes, atestiguados en Bretaña, Sur de las Galias y en Hispania, o de nombres de persona, como en irl. a. Brigit, la popular Brígida, que en el fondo se trata de una formación participial de femenino: goid. ${ }^{*}$ brigentī < ${ }^{*} b h r g h-n t \bar{i}$. Otro elemento significativo es el término nemeto-, atestiguado en celtibérico como primer elemento de nombre de ciudad (Nemetobriga en Ptolomeo, VI 37), con amplia difusión en los dialectos celtas: está docu-

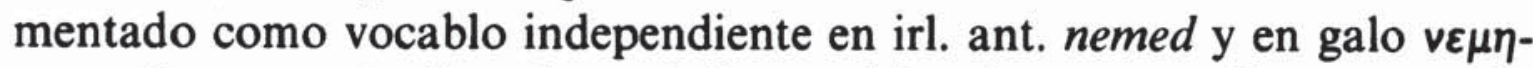
Tov, así como miembro de topónimos, al igual que en galés ant., p. ej., Eidnivet. Su sentido era de 'santuario, lugar consagrado', relacionado con lat. nemus 'bosque (sagrado)', gr. vénos 'bosque', a partir de la raíz *nem- 'repartir'.

A veces, junto al mantenimiento de viejos términos o a la innovación especializada de otros, es también significativa la pérdida de algunos. El nombre indoeuropeo para referirse al 'hijo' era *sunu-, con pervivencia en indio ant. sunúh, en germánico, p. ej., ingl. son o alem. Sohn, lit. sūnus, etc. Las lenguas célticas han perdido esta palabra y en su lugar han utilizado otras diferentes: antes de la contribución del celtibérico a la dialectología céltica, la cuestión quedaba reducida al irl. macc, $\tan$ frecuente aún en los apellidos irlandeses modernos, y su cognado map del galés ant., cuya protoforma ${ }^{*} m a k^{u} k^{u} o$-, aún reconocible en el gen. ogámico $M A Q Q I$, parecía tratarse de una innovación muy particular, sin ningún paralelo en el resto de las lenguas indoeuropeas. Que el término estaba ya en vigor en galo, aunque no es seguro que lo estuviera en el sentido de 'hijo', lo demuestra el epíteto de Apolo en la inscripción de Chamalières: Maponos. El celtibérico presenta, por el 
contrario, una palabra de la que sabemos con seguridad cómo empieza, ya que en los textos celtibéricos mejor comprendidos documentamos $\mathrm{Ce}$ como abreviación de la palabra 'hijo'. Si pensamos que la palabra gen$t e$, atestiguada en los difíciles textos de las páteras de Tiermes ${ }^{26}$ en dat. sg. concordando con el nombre de persona Stenionte, pueda ser la forma completa de la palabra para 'hijo' en celtibérico, deberíamos reconstruir una formación con el suf. de abstractos ${ }^{*}-t i-{ }^{27}$ de tema en $-i$ sobre la raiz *gen- 'engendrar': *gen-ti-, nom. en escritura ibérica ${ }^{*} C e n T i s^{28}$. Que esta raiz fue utilizada en todo el celta para referirse a la descendencia se comprueba a partir de los nombres de persona en -genus, $\tan$ frecuentes en todo el dominio: p. ej., celtib. Medugenus 'nacido de la hidromiel' > 'hijo de la hidromiel'; en galo la raíz fue utilizada para indicar el patronímico, como es frecuente en muchas inscripciones galogriegas de la Narbonense o de Italia: p. ej., la piedra bilingüe de Todi presenta Koisis Trutiknos con la versión latina Coisis Druti f. Por otro lado, el nombre de la 'hija', ahora documentado en galo de Larzac como duxtir (clara pervivencia de la palabra indoeuropea con paralelos en ingl. daughter o en gr. Эuүátᄁp), fue suplantado en el propio galo posterior por gnat $(h) a$ y en irl. por una formación novedosa sobre la misma raíz ${ }^{*}$ gen-: ${ }^{*}$ eni-genā $>$ ingen. Es de suponer, por tanto, que en todo el celta se perdió ${ }^{29}$ la vieja palabra ${ }^{*}$ sunu-, siendo sustituida por formaciones diferentes sobre la raíz *gen-, aún vivas en celtíbero y galo para 'hijo' y en irl. para 'hija', y que posteriormente en celta insular fue sustituida a su vez por la palabra expresiva ${ }^{*} m a k^{u} k^{u} o-$.

En las lenguas célticas insulares el verbo 'dar' se expresa mediante formaciones compuestas; así el irlandés usa de un verbo supletivo: no perfectivo do-beir, que consta de preverbio *to- más el verbo *bher-ō

${ }^{26}$ Sobre estos textos puede consultarse los comentarios de J. Siles, «Las páteras de Tiermes y un plato de Gruissan", Symbolae L. Mitxelena septuagenario oblatae (ed. J. L. Melena), Vitoria 1985, pp. 455-462.

${ }_{27}$ Sobre la existencia del sufijo - $t i$ - en celta, sin ampliación a -tiōn- como en irlandés, véase el teónimo galo Ucuetis, que K. H. Schmidt (nota 16) interpreta como innovación a partir de ${ }^{*} u k^{*}-t i-$.

${ }_{28} \mathrm{~J}$. Untermann me indica que el vocablo no necesita asterisco, ya que aparece atestiguado en el recién descubierto Gran Bronce de Botorrita, de inminente publicación. Como ya sugerí en el homenaje a Tovar y Michelena («Consideraciones sobre la fórmula onomástica y la expresión del origen en algunos textos celtibéricos menores", Studia indogermanica et palaeohispanica in honorem A. Tovar et L. Michelena [ed. F. Villar], Salamanca-Bilbao 1990, p. 305), gente de las páteras de Tiermes podría ser la expresión íntegra del nombre del 'hijo' en celtibérico.

${ }^{29}$ Hay que ser consciente de que los argumentos ex silentio pueden perder su validez en cualquier momento por aparición de nuevo material que documente la existencia del término en cuestión. Recuérdese lo ocurrido con galo duxtir para el nombre de la 'hija'. 
'llevar', y perfectivo torad- $<{ }^{*} t o-(p) r o-a d-d h-$, mientras que en galés solamente se atestigua el segundo verbo sin supletivismo: rhoddi, rhoi < *(p)ro-dh-. El galo presenta algunas formas verbales, que pueden ser puestas en relación con estas insulares: en primer lugar, una inscripción de Lezoux (Puy-de-Dôme) presenta una lectura no segura toberte, que se ha interpretado como pretérito del verbo 'dar', y por tanto, compuesto a partir de *to- más verbo *bher-; por otro lado, la importante inscripción bilingüe de Vercelli (Italia), redactada en el alfabeto de Lugano, atestigua una forma TośoKoTe, que ha sido interpretada de modo muy verosímil por Koch ${ }^{30}$ como $3 .^{a}$ pers. sg. del pretérito de un verbo ${ }^{*}$ to$k o n-d-e$, es decir, una formación compuesta de dos preverbios *to- y *kon- más la raíz verbal, que Koch deriva de * $\operatorname{deh}_{3}$ - 'dar', y la desinencia de perfecto $-e$. En celtibérico no tenemos atestiguado nada de esta naturaleza por ahora, ya que la única forma relativamente segura de pertenecer al verbo 'dar' es TaTus en el Bronce de Botorrita, de sentido imperativo, cuya forma ha recibido interpretaciones variadas; de todos modos, aparece muy claro que no se trata de una formación compuesta mediante preverbios más verbos con sentido de 'llevar' o 'colocar', de suerte que posiblemente haya que ver en su raíz $T a$ - la consecución del verbo indoeuropeo ${ }^{*} d e h_{3}$ - en grado pleno: $d \bar{a}-<{ }^{*} d \bar{o}$-.

\section{IV}

Este último ejemplo, en el que coinciden tres lenguas célticas, pero que no se extiende a todas las del grupo, nos introduce de lleno en el terreno de la dialectología céltica; es decir, en el del análisis e interpretación de los rasgos exclusivos o compartidos por algunos miembros del grupo en oposición a otros miembros, que han mantenido las formas antiguas o han innovado en otra dirección. La correcta valoración de los paralelos y de las diferencias es una ayuda inestimable para establecer la prehistoria de cada lengua particular, en especial las relaciones de proximidad o alejamiento con respecto a las otras lenguas del grupo, y de inferir alguna luz sobre procesos históricos externos.

Teniendo en cuenta que el celta común mantenía la labiovelar sorda ${ }^{*} k^{4}$, la diferencia histórica entre unas lenguas con velar (p. ej., irl. ceth(a)ir 'cuatro') y otras con labial (p. ej., gal. pedwar) fue sentida como el síntoma más claro de una división dialectal general en dos dominios diferenciados: celta Q- y celta P-. Cuando empezaron a surgir los docu-

${ }^{30}$ John T. Koch, «The Sentence in Gaulish», PHCC 3, 1983, pp. 187-8. 
mentos celtibéricos, su lengua fue clasificada entre las lenguas célticas Q- o goidélicas. Hoy día esta división ha perdido mucha de su fuerza clasificatoria, en primer lugar porque en el marco de un análisis fonológico más depurado ${ }^{31}$ no hay tanta diferencia entre dialectos $q u$ - y dialectos $p$-, si se tiene en cuenta que, en virtud del hueco estructural de la ${ }^{*} p$ en el sistema, pueden ser interpretados como dos alófonos de un mismo fonema $/ \mathbf{k}^{\mathrm{y}} /$, lo cual justificaría que en galo, frente al resultado normal [p] del numeral petru- en compuestos tengamos algunos nombres religiosos con qu-, como Equos, nombre de un mes en el calendario druida de Coligny. De todas formas la diferenciación debía estar cumplida ya para finales del s. Iv a. C., cuando Piteas de Marsella nos

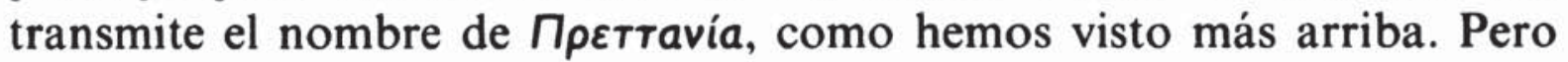
el golpe mayor a esta clasificación ha venido, sin duda, del lado del celtibérico, que no puede incluirse en uno de los grupos marcados por este criterio, sino que lo desborda por otro número de particularidades, y especialmente por el tratamiento de las sonantes vocálicas: p. ej., ${ }^{*} n>$ an. Además, como ya hemos avanzado en la introducción, una coincidencia en el mantenimiento de estados arcaicos no prueba ninguna unidad dialectal y así lo indicó para el celtibérico $\mathrm{Ch}$. Sleeth en una reseña (Word 3, 1947, p. 141 s.) al trabajo pionero de Tovar.

Estaría fuera de lugar discutir aquí una por una todas las características dialectales del celtibérico en comparación con las del resto de las lenguas célticas, pero algunas habremos de tratar, para mostrar que en todas, o en casi todas, el celtibérico muestra un comportamiento arcaico, conservador, sin que en ninguna ocasión parezca unirse a otro dialecto en alguna innovación específica. De ello sólo se obtiene una conclusión histórica: que los hablantes de lo que luego sería el celtibérico se separaron del resto de los celtas en una fecha temprana, llevando consigo una lengua que todavía empleaba unos recursos que fueron perdidos o cambiados por las demás, mientras que el celtibérico los guardó. Evidentemente, en su soledad hispana, rodeados de otros pueblos, algunos indoeuropeos no celtas y otros claramente ibéricos no indoeuropeos, fueron haciendo evolucionar su lengua de forma particular, y es de suponer que muchos términos y construcciones que no logramos entender deban su opacidad a esta larga evolución particular, como ya sugeria Tovar: "This is due to the fact that the ancestors of the people who engraved their inscriptions between the second century B. C. and the first or second A. D. were established in the territory of the upper

${ }^{31}$ Cf. E. P. Hamp, «Consonantal allophones in Proto-Keltic», Lochlann 1, 1958, pp. 209-17. 
Tagus, as we know from archaeology, since 7th century. We have therefore to reckon with several centuries of separate and independent development» ${ }^{32}$.

La flexión nominal proporciona buenas muestras de la especial vocación conservadora del celtibérico. Muchos de los étnicos grabados en las monedas en su forma de nom. de plural pertenecen a la clase flexiva de los nombres temáticos, es decir la de aquellas palabras que en latín o en griego configuran la segunda declinación. En las lenguas clásicas

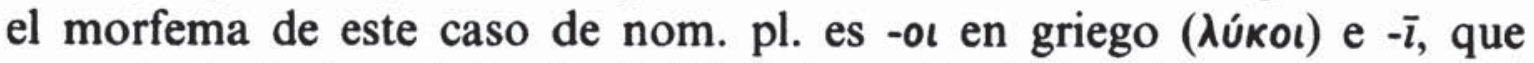
procede de *-oi, en latín (lup $\vec{\imath}$ ). El étnico galo de los Aresequani, que se entiende aproximadamente como "los que habitan en las cercanías del río Sequana", ofrece la desinencia $-i$, que procede de una anterior $-o i$ atestiguada en el patronímico de la inscripción gala de Briona, Tanotaliknoi 'los hijos de Dannotalos'; por una parte, los nominativos de plural del irl. ant. que terminan en una consonante palatal, cuya coloración se debe a un proceso asimilatorio a la desinencia que le seguía, luego perdida (irl. fir [f'ir'] 'varones' $<{ }^{*}$ uirî) y, por otra, la elevación que sufren las vocales medias o bajas radicales en los plurales galeses a causa de un proceso asimilatorio con la vocal alta de la desinencia (gal. ant. pl. beirdd 'bardos' < *bardi) exigen una desinencia ${ }^{*}-\bar{l}$. En cambio, el celtibérico presenta -ōs (areCoraTiCoś), ocasionalmente con cierre a u (uśamus). El resto de los grupos indoeuropeos nos muestra que la desinencia nominal originaria era $-\bar{o} s$ (scr. vṛkās, gót. wulfos, etc.), incluso el osco, lengua del grupo itálico al que pertenece también el latín, presenta la vieja desinencia (Núvlanús, lat. Nolani). Nos hallamos, por tanto, ante la circunstancia de que el celtibérico es la única lengua céltica conocida que ha mantenido la vieja desinencia nominal del nom. pl. de los temáticos, mientras que en todos los demás dialectos ha sido sustituida por la nueva desinencia *-oi de origen pronominal. El irl. ant. ratifica la existencia de la vieja desinencia, aunque la utilice sólo secundariamente en función de vocativo plural: firu < *uirōs.

Otro ejemplo curioso de distanciamiento del celtibérico lo constituye su forma de gen. sing. de esta misma flexión temática, que presenta la forma - $o$, tal como dejó establecido sin lugar a dudas J. Untermann en un famoso artículo ${ }^{33}$. Se han expresado varias hipótesis sobre el origen de esta forma, de las cuales la que la considera como antigua forma de

${ }^{32}$ A. Tovar, "The Celts in the Iberian Peninsula", Geschichte und Kultur der Kelten, Heidelberg 1986, p. 95.

${ }_{33} \mathrm{~J}$. Untermann, «Die Endung des Genitiv singularis der -o- Stämme im Keltiberischen", Beiträge zur Indogermanistik und Keltologie J. Pokorny gewidmet (ed. W. Meid), Innsbruck 1967, pp. 281-288. 
ablativo *-ōd es la que más aceptación ha recibido, a pesar de algunas dificultades de orden fonético, en concreto su falta de cierre a $\bar{u}$. Esta hipótesis tiene paralelos en balto-eslavo y experimenta un apoyo general en la motivación del cambio, que consiste en la necesidad de crear una forma de gen. sg. diferente de la del nom. sg. con la que originariamente se confundia, según atestigua aún el hitita. En este cometido las lenguas desarrollan estrategias diferentes: desinencia -os-io del ind. ant. y griego homérico, -so pronominal en germánico, desinencia ${ }^{*}-\bar{l}$ de origen poco aclarado en latín y celta. Recientemente Javier de $\mathrm{Hoz}^{34}$ ha argumentado en favor de la existencia de una forma de gen. sg. temática - $u$ en las inscripciones lepónticas más antiguas y en concreto en la de Prestino:

uvamokozis pliale९u uvltiauiopos ariuonepos siteś tetu. «Uvamogostis, hijo de Plialeto, dio/colocó sedes a los Uvtiavii y a los Arivonii/-ones.»

Junto a esta y otras inscripciones con formas temáticas de gen. sg. en $-u$, también se atestiguan otras formas seguras en $-i$, p. ej., kirati y atiaki de esgrafiados en vasos y algunos sobre piedra como alkouinos aśkoneti. De Hoz estima que el celta común tuvo las dos desinencias: la de genitivo en $-\bar{\imath}$ y la de ablativo en $-\bar{o} d$, dándose posteriormente en las lenguas particulares una fusión de las funciones con la elección de una sola de las formas; el lepóntico mostraría el estadio más antiguo con mantenimiento de ambas formas. Pudiera darse también que la desinencia $-i$ fuera más reciente en lepóntico, debida a contactos lingüísticos con el galo y otras lenguas itálicas, donde se atestigua esta desinencia. Es muy ilustrativa en este sentido la inscripción latina de Satricum, fechada hacia el s. v a. C., que con una clara desinencia -osio de gen. sg. temático (Popliosio Valesiosio = lat. Publi Valeri) muestra sin duda alguna la existencia de esta desinencia en un estadio antiguo de la lengua latina, luego sustituida totalmente por $-\bar{i}$. Es posible que originariamente hubiera una diferencia funcional entre ambas desinencias; parece claro que el ablativo $-\bar{o} d$, origen de la desinencia celtibérica $-o$ y de la lepóntica $-u$, se utilizaría genuinamente en contextos que indicaran origen o procedencia. Esto se aplicaba bien a la expresión de la filiación, sobre todo si el nombre para 'hijo' significaba originariamente 'nacido de', como hemos visto más arriba. Sólo hay que suponer que una secuencia como 'de Turos nacido', *Turōd gentis, análoga en todo punto al latino de Gaiuod patre prognatus del famoso elogio de Publio Cornelio Esci-

34 Javier de $\mathrm{Hoz}$, «El genitivo céltico de los temas en -o. El testimonio lepónticon, Studia indogermanica et palaeohispanica in honorem A. Tovan et L. Michelena (ed. F. Villar), Salamanca-Bilbao 1990, pp. 315-329. 
pión Barbado, se reanalizara posteriormente como 'de Turos hijo', donde el sentido de procedencia hubiera cedido al de genitivo de posesión.

El Bronce de Botorrita of rece varios ejemplos claros de coordinación de sintagmas mediante conjunciones coordinadas correlativas, que en virtud de su naturaleza átona se unen enclíticamente a la palabra que coordinan.

BelaioCumCue Ceniś CariCoCue Ceniś (Luzaga),

ToCoitośCue śarniCioCue (BB),

con la conjunción $/ k^{u} e /$, idéntica a la latina -que en su sentido y empleo

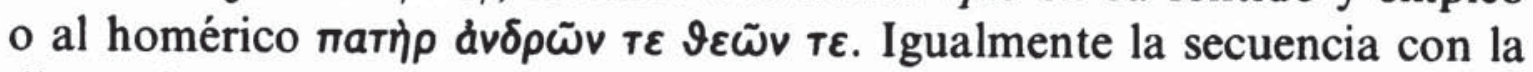
disyuntiva -ue: uranTiomue auseTi araTimue uniendo los dos Objetos del verbo auseTi o bien uerTaTośue Temeiue relacionando dos adverbios. El resto de los dialectos célticos presenta conjunciones cognadas, pero no las repite, sino que las coloca sólo tras el último miembro de la serie, como en latín domi bellique "en paz y en guerra»; p. ej., lepóntico Latumarui Sapsutai pe "a Latumaro y a Sapsuta", irl. arc. fer oa $n$-élat be(i)ch ro-ch lamethar forgull «una persona de la que escapan las abejas y que se propone testificar» (Schmidt, 1993, p. 74) ${ }^{35}$ o galo de Chamalières: buetid ollon reguc cambion «que sea ello completo y yo enderezco lo torcido" o de la inscripción gala de Lezoux: ...ieuri Rigani Rosmertiac «he dedicado a Rigana y a Rosmerta».

Pero junto a este fenómeno arcaico de la repetición, el celtibérico muestra en estas enclíticas otro rasgo no menos significativo: el mantenimiento de toda su integridad fonética, sin ningún rastro de apócope. Como luego veremos, las lenguas célticas insulares sufren en un período no muy anterior a sus primeros testimonios escritos, e incluso contemporáneo de las inscripciones ogámicas, unos procesos generalizados de apócope final y síncopa de diversas vocales átonas mediales. Así, p. ej., el gen. $M A Q Q I$ atestiguado aún con su desinencia en la mayoría de las inscripciones ogámicas se nos aparece como maicc, pronunciado [mak'], en irl. ant., mientras que su nom. sing. es macc [mak] sin palatalización de la consonante final, ya que la vocal desinencial apocopada era una vocal neutra - $a-$, procedente de la desinencia temática indoeuropea *-os. Resulta de esta manera que las funciones sintácticas, que en indoeuropeo y en los dialectos celtas continentales antiguos se expresaban mediante desinencias en el marco de una flexión, ahora se expresan en buena medida mediante la diferente naturaleza (palatal, neutra o velarizada) de la consonante final del tema. En galés también se produjo

${ }^{35}$ K. H. Schmidt, "Insular Celtic: P and Q Celtic», The Celtic Languages (ed. Martin J. Ball), Londres 1993, pp. 64-98. Cf. GOI, § 880. 
apócope de vocal final, aunque ésta, antes de elidirse, no causó ningún fenómeno de coloración de la consonante precedente como en irlandés. Como vimos antes, 'hijo' se dice en galés ant. map. De igual forma 'cinco' es en irl. ant. cóic [kōg'] y en galés pimp, ambas formas procedentes de ${ }^{*} k^{u} e n k^{u} e$, aunque no coincidan en ninguno solo de sus fonemas constitutivos. Frente a estos ejemplos, tanto el irlandés como el galés poseen conjunciones coordinativas negativas, que remontan a ${ }^{*} n e k^{*} e$ y que muestran en ambas lenguas consonantes velares: irl. $n a(c h)$, galés $n a(g)$. Comparando los dos ejemplos de apócope nos damos cuenta de que en realidad se trata de dos procesos distintos de diferente cronología: mientras que en los casos de los nombres plenamente tónicos el apócope se produce sólo en celta insular y tras el paso ${ }^{*} k^{\mu}>p$, cuando se trata de la conjunción átona y enclítica el apócope ha tenido lugar en una época muy anterior, cuando aún los llamados dialectos P- conservaban la labiovelar, afectando a los antecesores del irlandés, del britónico y del galo, pero dejando de lado al lepóntico y al celtibérico ${ }^{36}$. Este fenómeno de época antigua sugiere, pues, la idea de que tanto el celtibérico como el lepóntico se habían separado ya de la comunidad céltica en una época temprana, adquiriendo una posición de marginalidad, que no perderán en lo sucesivo ${ }^{37}$.

Acabamos de indicar, de pasada, que el celta insular sufre en una época preliteraria una reducción fortísima de la flexión nominal en irlandés ${ }^{38}$ y su total eliminación en britónico, con posterioridad a la dominación romana. Evidentemente, el celtibérico, datado en los siglos inmediatos al cambio de era, presenta una tipología morfológica totalmente flexiva, acorde con el galo y con el resto de las lenguas indoeuropeas antiguas de Europa y Asia. Es, por tanto, normal que el celtibérico nos documente una serie de casos perdidos en el celta insular. Con todo, hay testimonio de algunos casos, como el locativo de los temáticos, apreciable en Temei del BB o en CorTonei de la ciudad Cortonum en una plancha broncínea o śomei del pronombre demostrativo, del que no había rastro en ninguna otra lengua céltica. Por otro lado, el galo también ha contribuido a completar la imagen de la flexión del

36 J. Gorrochategui, "Descripción y posición lingüística del celtibérico», Memoriae L. Mitxelena magistri sacrum (edd. Joseba A. Lakarra et I. Ruiz Arzalluz), San Sebastián 1991, p. 13. Cf. GOI, § 868.

37 Véase en este sentido, Javier de Hoz, "The Celts of the Iberian Peninsula", ZCP 45, 1992, pp. 1-37.

${ }^{38}$ Las inscripciones ogámicas muestran este proceso de pérdida de las desinencias, desde nombres como Voteco-rig-as (gen. sg.) con mantenimiento de todas las vocales mediales y la desinencia atemática, hasta Vergoso < *uiro-gustouss con pérdida de vocal $-o$ - medial y reducción del diptongo de la desinencia. 
celta común, ya que mantiene en vigor, p. ej., los casos de dativo (-ui:

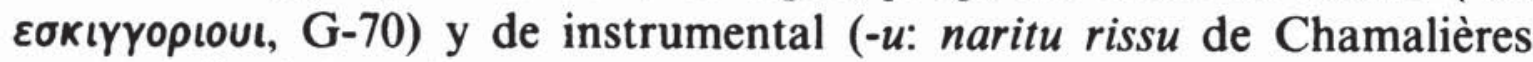
(por medio del escrito mágico»), a pesar de que se aprecien ya síntomas de sincretismo, como el empleo del instrumental en lugar del dativo (Magalu), circunstancia que es la reconstruible para el antecesor inmediato del irlandés.

La inscripción gala de Larzac, publicada en 1985 por M. Lejeune y colaboradores $^{39}$, ha confirmado la existencia de un gen. sg. de los temas en $-a$, eminentemente femeninos, en -ias (paullias) y de un ac. sg. en -in (seuerin). Los celtistas ya habían propuesto con anterioridad que las formas irlandesas de ac. sg. y de gen. sg. de este tipo flexivo, como puede apreciarse en el nombre de la 'tribu': ac. túaith [tūa९'], gen. túaithe [tūa $\vartheta^{\prime}$ ], remontaban a unas desinencias *-im/-em $\mathrm{e}^{*}$-ias respectivamente. La cuestión interesante estriba en dilucidar si estas innovaciones, de las que no participan ni el celtibérico ni el lepóntico, son el resultado de un mismo proceso común o por el contrario son el resultado de procesos paralelos pero independientes en cada lengua. No conocemos la antigüedad del proceso en irlandés, pero en galo parece ser que se trata de un hecho relativamente reciente, y quizá dialectal, ya que el galo de Italia, que es más antiguo que el de la Galia central en dos o tres siglos, presenta un ac. sg. en -am y un gen. sg. en -as: es decir, lo esperado desde el punto de vista indoeuropeo y coincidente con los dialectos conservadores celtibérico y lepóntico. No cabe duda de que para el cambio de era el irlandés y el galo eran dos lenguas claramente diferenciadas, de modo que en mi opınión se trata de dos procesos paralelos ${ }^{40}$. Sin embargo, algunos lingüistas se han esforzado en hallar una explicación única a ambos procesos y entre ellos cabe mencionar el intento de $\mathrm{L}$. Aldo Prosdocimi ${ }^{41}$ por el hecho de que incluye en la discusión datos hispanos, en concreto del área lingüística lusitana. En su opinión la atestiguación de las formas crougin (como ac. sg. en una inscripción de Mosteiro de Ribeira en Xinzo de Limia) y crougeai (como dat. sg. de la misma palabra en la grande de Lamas de Moledo) viene a confirmar la

${ }^{39}$ M. Lejeune avec L. Fleuriot, P.-Y. Lambert, R. Marichal et A. Vernhet, Le plomb magique du Larzac et les sorcières gauloises, París 1985, tirada aparte de Études Celtiques 22, pp. 88-177.

$40 \mathrm{~J}$. Gorrochategui, «La declinación céltica de los temas en - $a$ y los datos hispanos», Indogermanica et Caucasica (R. Bielmeier y R. Stempel, edd.), Berlin-Nueva York 1994, pp. 316-330 (Festschrift K. H. Schmidt).

${ }^{41}$ L. A. Prosdocimi, "L'iscrizione gallica del Larzac e la flessione dei temi in -a, -i, -ja. Con un 'excursus' sulla morfologia del lusitano: acc. crougin, dat. crougeain, IF 94, pp. 190-206. 
antigüedad de la flexión atestiguada por el irlandés y el galo reciente y de paso constituye un fuerte argumento para la inclusión del lusitano en el grupo lingüistico celta. Su explicación exige, sin embargo, la reconstrucción de un tipo flexivo heteróclito o mixto, para el que no hay evidencias en ningún otro grupo indoeuropeo, como tipo más antiguo y general del celta, y que ha sufrido una nivelación o simplificación en celtibérico, lepóntico y galo de Italia, resultando una flexión coincidente totalmente con la de los temas en - $a$, plenamente conocida y atestiguada en todas partes. Es una explicación que atenta contra el principio de simplicidad en reconstrucción lingüística, que es conocido bajo el nombre técnico de «navaja de Occam». Pero, desde el lado de la documentación hispana, Prosdocimi se apoya para la forma crougin en una inscripción perdida, cuya lectura presenta en mi opinión fuertes sospechas de corrupción. He intentado demostrar que en la lectura crougin transmitida por el padre Sarmiento hay que leer en realidad CROVGIAI con una ligadura de las tres últimas letras ${ }^{42}$. De ello resultaría el nombre de una divinidad indígena en dat. sg., nada excepcionalmente extraño en el horizonte lingüístico y cultural de la zona en ese período, cuyo paralelo hallamos, además de en la citada inscripción de Lamas de Moledo, en otra de Freixosa ${ }^{43}$.

Una de las características más llamativas del verbo celta insular, que se muestra con más claridad en los datos del irlandés antiguo, consiste en que sus formas flexivas, es decir, las personas de la conjugación de los tiempos verbales, aparezcan bajo dos formas diferentes, en virtud de criterios sintácticos: las llamadas formas absolutas, cuando el verbo va a comienzo de oración declarativa afirmativa, y formas conjuntas, cuando va unido a una partícula conjunta, como la negación o la interrogación: p. ej., biru 'yo llevo' frente a ni biur 'yo no llevo'. La forma conjunta también se usaba en los verbos compuestos con uno o más preverbios: p. ej., do-biur 'yo doy'. Aunque este juego de formas ha desaparecido casi por completo en irlandés moderno, todavía quedan restos en las llamadas formas dependientes de algunos verbos: p. ej., el verbo sustantivo, muy parecido en su uso al del español 'estar' frente al copulativo 'ser', tiene una forma independiente tá y una dependiente fuil, que procede de la forma conjunta del irl. ant. fil. Una de las expli-

${ }^{42}$ J. Gorrochategui, «En torno a la clasificación del lusitano», Studia palaeohispanica, Actas del IV Coloquio sobre Lenguas y Culturas paleohispánicas, Vitoria 1987, pp. 77-91, esp. $86 \mathrm{~s}$. $557-62$.

43 J. L. Inés Vaz, "Crouga, uma divinidade indigena", Beira Alta 43, 1984, pp. 
caciones más extendidas de este fenómeno lo hacía proceder del sistema de desinencias primarias y secundarias del indoeuropeo, bien reconstruido a partir de los datos griegos e indo-iranios, dentro del cual las desinencias primarias se reservaban para los tiempos de presente (y más tarde el futuro) y las secundarias para los tiempos de pasado (aoristo e imperfecto); pero teniendo en cuenta que el juego de formas absolutas y conjuntas nada tiene que ver con una distribución entre tiempos de presente y pasado, sino que se aplica a la mayoría de ellos (GOI, § 542), incluso se remontaba su origen a un estadio indoeuropeo anterior, en el que se presumía que hubiera libertad de empleo de ambas tanto en temas de presente como de pasado. Esta hipótesis dejaba sin explicar ciertos comportamientos gramaticales, como, por ejemplo, la falta de lenición tras la forma absoluta de la cópula. Si se considera que la 3. ${ }^{a}$ pers. sg. de la forma absoluta procede de la desinencia primaria indoeuropea ${ }^{*}-t i$, mientras que la conjunta lo hace de la secundaria ${ }^{*}-t$, entonces la consonante inicial del atributo que sigue inmediatamente a la forma proclítica de la cópula *esti debería sufrir lenición, es decir, un proceso fonológico por el que toda oclusiva se fricatiza o espirantiza en irlandés $\left({ }^{*} \mathrm{t}>\vartheta<\mathrm{th}>\right.$; $\left.{ }^{*} \mathrm{~d}>\delta<\mathrm{d}>\right)$. Sin embargo, no ocurre nada de esto.

La documentación del celta continental, aun siendo excepcionalmente fragmentaria en el ámbito de la morfología verbal, no avala este juego insular entre formas absolutas y conjuntas. Hay que tener en cuenta que la mayoría de las formas documentadas en los epígrafes se refieren a nociones de pasado o perfecto, del tipo 'he dedicado', 'he dado', 'he colocado', 'he hecho', etc., para lo cual se utilizan formas antiguas de aoristo o de perfecto, así como otras nuevas creadas mediante combinación de temas y desinencias de origen diferente.

En celtibérico el empleo de la escritura ibérica, que no permite la discriminación nítida entre oclusivas aisladas y acompañadas de vocal, dificulta la fijación de la desinencia: bien primaria como parece derivarse de la repetida forma - $T i$ en que acaban todas las formas verbales no imperativas del Bronce de Botorrita, y que cuadra bien con formas que se interpretan como presentes de indicativo como uersoniTi $\left({ }^{*}\right.$ uper-son-

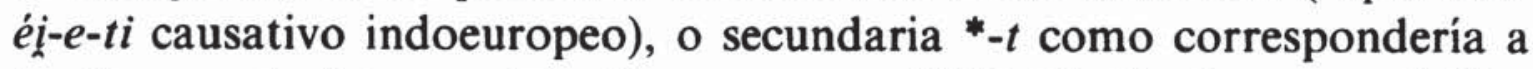
las formas de futuro-subjuntivo como amBiTiśeTi. No hay que olvidar que la inscripción grande de Peñalba de Villastar presenta en escritura latina SISTAT, que aparentemente es un presente de indicativo. Aunque bien pudiera ser que esta inscripción, más reciente en el tiempo, fuera testigo de una pérdida de $-i$ final en el celtibérico más reciente; al menos hay algunos otros rasgos de la inscripción que favorecerían la 
idea de un estadio de lengua más moderno (cf. Villar sobre la expresión del locativo ${ }^{44}$ ).

Pero, por otro lado, hallamos en galo algunas formas verbales que, en comparación con otras, muestran unas adherencias sufijadas, que se han entendido como pronombres anafóricos enclíticos: p. ej., frente a una forma de pasado prinas, que se interpreta como un antiguo aoristo sigmático * $k^{u} r i-n a-s-t$ 'compró, ha comprado', existe legasit 'colocó, ha colocado', que remonta al mismo tiempo $\left({ }^{*} \operatorname{leg} h-\bar{a}-s-t\right)+-i t$, que se entiende como el pronombre id, presente también en la forma verbal buetid de Chamalières 'que sea ello'. La sufijación de elementos enclíticos a las formas finitas del verbo se da también con pronombres personales: en la inscripción de Chamalières encontramos ejemplos de ello como en exsops pissíu-mii 'ciego, veré yo', forma de futuro sigmático -sie/o- sobre la raíz ${ }^{*} k^{u} e i s-$ o uediiu-mi 'honro, venero', presente de indicativo, formas ambas que añaden el pronombre de $1 .^{a}$ pers. $m i$ a la forma verbal que acaba en $-u$, procedente del IE ${ }^{*}-\bar{o}$ en sílaba final. Junto a estas formas hallamos en la misma inscripción otras sin el pronombre enclítico: regu-c, aunque con la enclisis de la conjunción copulativa, tal como hemos comentado arriba. En las lenguas célticas insulares se fortalece esta tendencia a la afijación pronominal; las formas verbales absolutas llevarán pronombres sufijados y los complejos verbales consistentes en Preverbio + Verbo las infijarán dentro de sí: p. ej., irl. a. ad-ci 'él ve' y atom-chi 'él me ve' con el pronombre infijado (clase B), que a la vez produce lenición de la consonante inicial de la raiz verbal. Este fenómeno, que constituye una de las características tipológicas más significativas del verbo celta insular, está apuntado en el verbo galo, según el análisis de algunas pocas formas verbales: p. ej., TOMEZECLAI [tomedeklai] de la inscripción de Voltino, que Meid (Zur Lesung und Deutung gallischer Inschriften, Innsbruck 1989, p. 21 ss.) interpreta como una forma de perfecto compuesto de un preverbio to tónico al que se sufija el acusativo del pronombre personal de 1. " pers. med más otro

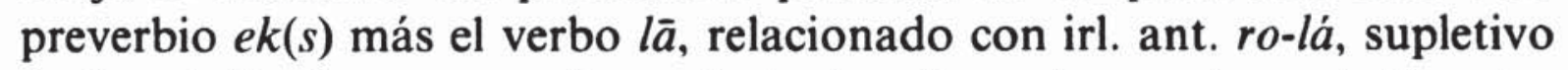
de fo-ceird 'colocar, poner', por lo tanto, algo así como 'me erigió, colocó', etc. El mismo esquema se atestigua en la forma tośokote de la inscripción bilingüe de Vercelli, citada y comentada arriba, que según análisis de Koch hay que entender como procedente de *to + pron. demostrativo śo $+k o(n)-d H_{3}-e$.

La tendencia a la afijación se comprueba también en la posición

44 F. Villar, "Le locatif celtibérique et le charactère tardif de la langue celtique dans l'inscription de Peñalba de Villastar», ZCP 44, 1991, pp. 56-66. 
pospuesta del pronombre relativo en galo. Hasta el momento se han detectado dos claras oraciones de relativo en el corpus epigráfico galo: 1) en la inscripción de Alesia: etic gobedbi dugiiontiio Ucuetin in Alisiia "y a los herreros que veneran a Ucuetis en Alesia", donde vemos que a la forma verbal en $3 .^{a} \mathrm{pl}$. dugiiont( $(i)$, que encabeza su oración, se sufija el pronombre relativo invariable -io, y 2) la de la inscripción de Chamalières: etic Secoui toncnaman toncsiiontio "y los Segouii que jurarán un juramento" con el mismo esquema, en el que se aprecia el recurso estilístico a la figura etymologica conseguida entre el objeto y el verbo, 3. ${ }^{\mathrm{a}}$ pers. pl. del futuro en *-sio-: tonc-sio-nt $(i)+$ relativo invariable $-i o^{45}$.

Esta construcción gala de las oraciones de relativo está relacionada con una de las características más llamativas de la morfología verbal insular: la existencia de formas especiales de relativo en ciertas personas verbales; así, p. ej., en irl. ant. la $3 .^{\text {a }}$ pers. sg. del verbo 'venir' es téit $<{ }^{*}$ steigh-e-t(i), mientras que la forma de relativo es téite, que Thurneysen ya explicó como procedente de *steigh-e-t(i) + io. Siguiendo el esquema general del emplazamiento de las enclíticas en la segunda posición del complejo verbal tras el primer preverbio tónico, en consonancia con lo prescrito por la ley de Wackernagel, resultarán oraciones de relativo, cuya característica definitoria frente a la no relativa residirá en la lenición (o nasalización) que sufra la consonante inicial de la raíz verbal: si $a d$-cí significa 'él o ella ve', una oración como 'el hombre que ve al muchacho' se diría en irl. ant. in fer ad-chí in macc. < ${ }^{*}$ sindos uiros ad-io- $k^{u} i s-e-t(i)$ sindom $m a k^{u} k^{u} o m$, donde la lenión de chi se debe imputar a un elemento vocálico precedente, en concreto al relativo átono -io- infijado entre el preverbio inicial y la raiz verbal.

La combinación de todos estos datos nos lleva a concluir que: 1. por un lado, el celtibérico no participa en esta tendencia general del celta insular, apuntada muy claramente en galo, hacia la afijación de pronombres en las inmediaciones del verbo y en especial en la configuración de la nueva estructura de la oración de relativo; permanece oscura, por ahora, la desinencia $-s$ de la forma de imperativo TaTus del Bronce de Botorrita ${ }^{46} ; 2$. que en algunas de estas sufijaciones habrá que hallar,

${ }^{45}$ K. H. Schmidt, «The Gaulish Inscription of Chamalières», BBCS 29, 1981, p. 266 ss.

${ }_{46}$ Me recuerda Koldo Sainz que la posición en final de frase no sería la más adecuada para la sufijación enclítica del pronombre anafórico, de modo que: 1) o no se trata de un pronombre anafórico, o 2) la posición del verbo ha variado a partir de otra inicial anterior. Parece bastante firme la idea de que el CI era lengua SOV, tal como hemos indicado arriba, de modo que no hay pruebas de peso para hacer pensar lo contrario. De todos modos, y sólo en los imperativos, podría pensarse que el verbo iniciara una oración (cf. el uso románico) y se le sufijaran enclíticamente los 
probablemente, como apuntaba W. Cowgill ${ }^{47}$, el origen del juego insular entre formas absolutas y formas conjuntas.

No ha pasado desapercibida la circunstancia de que también en las lenguas románicas se da un fenómeno muy parecido de aglutinación de pronombres en los aledaños verbales; ejemplos como el del portugués moderno Ser-nos-ía muito grato, con inclusión del pronombre entre el infinitivo y el auxiliar, que ha conservado hasta nuestros días un comportamiento que era normal en español hasta el s. XVII como en dar le has, venir vos edes 'os vendréis', recuerdan vivamente a los procesos descritos arriba para el celta. Han sido utilizados, junto con otros argumentos, para justificar una fuerte influencia de sustrato de las lenguas célticas sobre las románicas. De todos modos, el hecho de que el celta de Hispania no presente evidencia de tales innovaciones resta fuerza a la tesis sustratista general y refuerza los intentos de explicación del fenómeno a partir de criterios tipológicos generales sobre la estructura sintáctica y la evolución de los sistemas internos de las lenguas.

Creo que lo expuesto hasta ahora presenta de modo suficientemente revelador la naturaleza arcaica del celtibérico en el conjunto de las lenguas célticas, que en conjunción con el conocimiento general de las culturas prehistóricas y los posibles movimientos de pueblos y culturas en los últimos períodos del Bronce y los primeros del Hierro llevan a pensar en una temprana separación de los habitantes del celtibérico de lo que se considera el núcleo de los hablantes de celta. En el largo período de permanencia en Hispania, desde su llegada hasta la redacción de los textos, el celtibérico tuvo que evolucionar de modo independiente perdiendo cierto material heredado y creando otro nuevo, bien a partir de elementos propios bien mediante material tomado en préstamo de alguna de las lenguas vecinas. Hemos comprobado que la celticidad originaria del celtibérico nos ayuda en la interpretación de los arcaísmos de la lengua, en aquello que ha conservado y que conocemos tanto por el resto de las lenguas célticas como por el indoeuropeo en general ${ }^{48}$. Por

pronombres; habría que suponer después que el conjunto amalgamado se utilizó como forma inseparable de imperativo, ocupando la posición final propia de una forma verbal declarativa.

${ }^{47} \mathrm{~W}$. Cowgill, "The origin of the Insular Celtic conjunct and absolute verbal endings", Flexion und Wortbildung. Akter der V. Fachtagung der idg. Gesellschaft (ed. H. Rix), Wiesbaden 1975, pp. 40-70.

${ }^{48}$ El recurso a los datos de ambas partes es necesario tanto para la obtención de una idea correcta de la posición y evolución de la lengua, como para la interpretación textual de los difíciles y fragmentarios textos conservados. Debo matizar, por tanto, las palabras de W. Meid (Gaulish inscriptions, Budapest 1992) referidas al galo: «the Insular Celtic languages are of no great help; they are attested much later, 
otro lado, las comparaciones dialectales intracélticas, en los casos escogidos que hemos tratado aquí, también confirman este aspecto arcaico del celta hispánico, el cual en ocasiones se ve acompañado del irlandés y en otras del lepóntico.

JOAQUiN GoRRochategui

have changed considerably in the meantime, and the subject matter of their texts is quite different" (p. 6, n. 10), ya que la prueba a contrario, es decir, la de la inestimable ayuda de las lenguas célticas insulares, la ofrece el propio Meid en su libro con el recurso continuo a los paralelos insulares para las mejores explicaciones de los datos galos. 